\title{
Children's pain: A mandate for change
}

\author{
Andrea L Brennan-Hunter MN RN
}

\section{AL Brennan-Hunter. \\ Children's pain: A mandate for change. \\ Pain Res Manage 2001;6(1):29-39.}

There have been tremendous research advances in the past 15 years in knowledge about children's pain, and strategies for recognizing and managing that pain. However, the clinical care of children in pain remains a challenge. Children's pain continues to be frequently unrecognized, dismissed or ineffectively managed. A loud call for change is being voiced by physicians, nurses, children and their families. A review of the literature was conducted to document this issue. Starting with a MEDLINE search of the key word 'child* + pain' and continuing with a snowball technique, articles and resources addressing children's pain were collected. Resources presented or published after 1990 were particularly sought because they theoretically reflect both current knowledge about children's pain and the implementation of this knowledge in practice. Unfortunately, although information on pain is available to help children, in many instances, it is not being used. The purpose of the present paper is twofold - to present an overview of current knowledge of children's pain, and factors that hinder its effective assessment and management; and to present a mandate for change. Children's postoperative pain is highlighted in this paper as an example of the gap between pain knowledge and clinical practice. Although treatment strategies differ across different types of pain, children's conditions and ages, the principles and mandate for change discussed in this paper are directly relevant to all categories of children's pain.

Key Words: Children's pain; Pain management; Postoperative pain

\section{La douleur des enfants : un mandat de changement}

RÉSUMÉ : Au cours des quinze dernières années, les recherches et les connaissances sur la douleur chez les enfants ont fait des progrès remarquables, de même que les stratégies pour reconnaître et traiter cette douleur. Toutefois, les soins cliniques des enfants en douleur font toujours problème. Encore aujourd'hui, les douleurs des enfants sont souvent non diagnostiquées, négligées ou mal soignées. C'est pourquoi des médecins, des infirmières, des enfants et leurs familles lancent un appel au changement. Un examen de la littérature a été effectué en vue de documenter la question. Une première recherche sur MEDLINE des mots clés 'child* + pain' puis le recours à une technique en boule de neige ont permis de rassembler les articles et ressources portant sur la douleur des enfants. Les ressources présentées ou publiées après 1990 ont été particulièrement recherchées, puisqu'elles devraient refléter à la fois l'état actuel des connaissances sur la douleur chez les enfants et la mise en pratique de ces connaissances. Trop souvent, malheureusement, l'information sur la douleur des enfants, bien qu'elle soit accessible, n'est pas utilisée pour leur venir en aide. Le but du présent article est donc double : présenter un aperçu des connaissances actuelles sur la douleur chez les enfants, et les facteurs qui font obstacle à l'évaluation et au traitement efficaces de celle-ci; et présenter un mandat de changement. Les douleurs postopératoires des enfants serviront ici d'illustration de l'écart qui existe entre les connaissances sur la douleur et la pratique clinique. Bien que les stratégies thérapeutiques diffèrent suivant les divers types de douleur, l'état des enfants et leur âge, les principes et le mandat de changement discutés dans cet article s'appliquent directement à toutes les catégories de douleur des enfants.
$T^{2}$ reatment of pain is a familiar, yet elusive, clinical challenge for many health care professionals. In the past 20 years, a new understanding of identifying, assessing and managing pain evolved, and continues in research initiatives. Unfortunately, clinical care has lagged behind in implementing the new knowledge relating to pain, particularly in the care of children.

A history of nonrecognition, dismissal and undermedication of children's pain is well documented. In 1968, Swafford and Allen (1) published a study that recorded postoperative analgesia among children. Two of 60 postoperative children received analgesic medication, and adolescents and older school-aged children complained of more pain than infants and young children in the study. On this basis, the researchers concluded that, because children did not receive analgesics, they do not need them; because 'children do not need postoperative analgesics', such medications should be avoided whenever possible; and because adolescents and older children complained of more pain than the infants and young children in the study, the researchers suggested that infants 
and young children are developmentally less sensitive to pain. Although flawed paths of logic, these assumptions were widely accepted and continue to plague present day clinical care of children of all ages.

In a classic study, Eland and Anderson (2) documented the undermedication of children for postoperative pain and extreme differences in the patterns of postoperative analgesic administration for children versus adults. Using chart reviews to collect data, Eland and Anderson (2) found that 12 of 25 children in the study received analgesics after procedures such as amputations, nephrectomies and repairs of atrial septal defects; all of the adults $(n=18)$ received analgesics. The 12 children who received analgesics received a total of 24 doses during their hospital stays compared with 372 narcotic and 299 non-narcotic doses of analgesics administered to the adults. Unfortunately, clinical care did not change as a result of this study. Similar findings were documented in subsequent studies $(3,4)$.

Since 1985, a wealth of evidence has documented that children, including premature and term infants, can and do feel pain; that long held myths and misconceptions about children's pain have been barriers to effective pain assessment and management; and that safe and effective strategies (both pharmacological and nonpharmacological) are readily available to manage children's pain. Unfortunately, although the information is available to help children, in many instances, it is not being used. Institutions have lagged behind research in implementing changes for numerous, and often invalid or inadvertent, reasons (5-8). The purpose of the present paper is twofold - to present an overview of current knowledge of children's pain, and factors that hinder its effective assessment and management; and to present a mandate for change. Change must be coordinated, comprehensive and multidisciplinary. While reading this paper, health care professionals are asked to consider their own practices and those of their respective clinical agencies to identify ways of making each level of practice more knowledge-based, more comprehensive in its communication with other disciplines and, ultimately, more effective in providing children's care. Children's postoperative pain is highlighted in this paper as a clear example of the gap between pain knowledge and clinical practice. Similar gaps and clinical barriers are present in other areas of children's pain care. Although treatment strategies differ across different types of pain and children's conditions and ages, the principles and mandate for change discussed below are directly relevant to all categories of children's pain.

\section{KNOWLEDGE OF CHILDREN'S PAIN}

In the past 10 years, recognition and alleviation of children's pain have evolved from virtual nonattention to a focus of major research and clinical efforts to identify, interpret, and manage pain effectively and humanely. Knowledge abounds in the areas of monitoring the reactions of infants and older children to pain; documenting the adverse implications of pain on children's health and postoperative recovery status; developing and validating assessment tools; refining drug and technology protocols; and more recently, the promotion, facilitation and implementation of multidisciplinary teams to transfer new knowledge into practice.

An important finding arising from research in each area is the resounding insight that adults and children cannot be equated in the interpretation of pain. It is known that children feel pain, but it is unknown whether the level of pain experienced during a procedure is more or less than that experienced by adults. There is no evidence to suggest that the pain level is less, and some researchers suggest that it may be more. Children do not, and often cannot, interpret pain or react to it as adults do. On these bases, a separate approach is mandated for assessing, interpreting and managing children's pain.

\section{Children's perception of pain}

In direct contradiction to the view that children (particularly infants) do not feel pain, the work of Anand (9) and others $(8,10-18)$ during the past 15 years in documenting the reactions of premature and term infants to pain, and the increase in morbidity and mortality among infants who received little or no analgesia during or after procedures, has been considered revolutionary, and, indeed, the impetus for needed research and change in clinical care. Based on Anand's work (9) and the work of investigators pursuing similar lines of research, it is now known that, although the nervous system is still growing throughout childhood, the anatomical requirements for pain perception are in place before birth $(9,10,13,19-24)$. In fact, infants may be more at risk of perceiving painful stimuli than adults because the density of nociceptive receptors in cutaneous membranes in newborns is equal to or greater than that in adults $(15,20,21)$, and control mechanisms in the spinal cord and central nervous system may be lacking in premature and very young infants $(13,15,23)$. Because infants older than one month of age have essentially adult pharmacodynamics in metabolizing morphine and other analgesics (25) - and even premature infants can safely metabolize analgesics titrated for their age, size and drug used $(16,19,26-29)$ - practices of nonmedication for neonatal and infant pain during and after procedures on the basis of a child's age seem deliberately cruel.

\section{Negative consequences of postoperative pain}

Treatment of postoperative pain presents a clinical dilemma because the body is undergoing a mild to severe imbalance in response to an operative procedure. Adding an analgesic that goes beyond a traditional, postoperative medication regimen may seem more risky than prudent. Health professionals have been reluctant to use even simple regimens, considering it to be safer to withhold narcotics than to give them $(17,29)$. However, just the opposite is the case.

Rogers (30) contended that a long-standing pattern of treating children's pain has been established, as follows. In an effort to avoid the side effects and possible complications of analgesics, particularly opioids, the analgesics are withheld. Because the side effects and complications do not occur, the decision seems justified, and a policy of nonmedication or low medication administration is reinforced. In truth, the need 
for analgesia, when indicated, far outweighs any reason to withhold analgesics. Multiple researchers have outlined the specific physical, physiological and psychological effects of acute pain, particularly among premature and term neonates $(9,13,15,19,20,31-34)$. Ross et al (35) contended that "the effective use of analgesia alleviates pain and suffering, helps prevent postoperative complications and improves the psychological and physiological welfare of the patient". More specifically, Schechter et al (8) stated:

\section{The consequences of not treating or ameliorating acute pain can therefore be catastrophic. The unchecked release of stress hormones by untreated pain may exacerbate injury, prevent wound healing, lead to infection, prolong hospitalization and even lead to death. These deleterious effects are greatest in the sickest and frailest of patients. ... Thus the concept that a critically ill child or newborn is too 'sick' to be treated with analgesics may need to be changed completely. Indeed these patients may be too 'sick' not to be treated.}

More recently, long term sequelae of painful episodes have been recognized, spurring the investigation of children's ability to remember pain. Although infants and small children do not seem to have context-specific memories of previous pain $(15,19,36)$, the consistent documentation of stress and distress responses after noxious events provides evidence for a different type of 'remembering'. Several researchers have documented a change in infants' behaviour after painful procedures, particularly among premature and young term neonates who undergo repeated procedures as a part of their care $(15,19,32)$. The infants become hypersensitive to subsequent procedures and over time have also demonstrated a crossover of their pain reaction to non-noxious stimulation.

The impact of pain extends beyond hospitalization and neonatal procedures. Taddio and colleagues (37) documented infants' responses to immunizations and found that infant boys who had been circumcised as neonates were more distressed than boys who had not been circumcised. In a review of literature outlining the consequences of pain (32), increased somatization was documented among 4.5-year-old children who had undergone numerous procedures as neonates. Similarly, eight- to 10 -year-old children who had neonatal histories of numerous procedures reported higher pain ratings during a projected pain exercise than the ratings reported by children of the same age who did not have such histories (19). In investigating sequelae after day surgery, Kotiniemi and colleagues (38) found that children who had had pain after day surgery exhibited negative behaviours (eg, difficulty eating or sleeping, mood changes) for up to four weeks after the surgery. This was more pronounced in the younger children in the study. Weisman et al (39) explored the effect of inadequate procedural analgesia on subsequent procedures. They too found that, among the younger children in their study (those younger than eight years of age), pain ratings were consistently higher for children who had received placebo during the first procedure. Lastly, in a comprehensive review, Zeltzer et al $(40,41)$ described the long term effect of unresolved acute pain in potentiating chronic pain syndromes and altered interactions after the painful episode.

\section{The nature of pain: Impact on recognition and assessment in children}

The International Association for the Study of Pain (IASP) has defined 'pain' as “an unpleasant sensory and emotional experience associated with actual or potential tissue damage or described in terms of that damage" (42). A further refinement stated that "pain is always subjective. Each individual learns the application of the word through experiences related to injury in early life" (43). However, the amount of pain experienced does not always equate with the amount of tissue damage $(25,44)$, nor is it clear that one's response to pain must be learned (45). Focusing on the subjective nature of pain, McCaffery and Beebe (29) contended that "pain is whatever the experiencing person says it is, existing whenever the experiencing person says it does". Based on this latter definition, self-report is considered to be the most reliable and valid estimate of pain intensity, quality and location $(24,34,46)$.

IASP's definition of pain and the recognition of the subjectivity of pain have allowed tremendous growth in responsive, sensitive and individualized care of people with pain (45). However, these same statements, if accepted as outlined, also limit recognition of pain in many infants and children in two ways. First, the statements do not encompass the experience of neonates, young children or other children who cannot verbally report their pain. Anand and Craig (45) contended that the perception of pain is an inherent quality of life itself; that it does not require a previous painful experience; and that it is, in fact, 'self-reported' in infants' behavioural reaction to pain. Anand and Craig's (45) position is strongly supported by the wealth of evidence that infants $d o$ feel pain and $d o$ react to it in recognizable ways.

The second problem arising from the definitions of pain outlined above involves the issue of self-reporting. Although regarded as the standard for recognizing and assessing another individual's pain, self-reports do not necessarily match the level of pain experienced. Anand and Craig (45) noted:

\section{Relationships between feeling pain and reporting pain are highly context-dependent. They reflect who is eliciting the self-report, the methods used to assess pain, the underlying reasons for eliciting the description of pain and the individual's perception of the consequence of reporting pain.}

Children may be reluctant to report pain. As a rule, children tend not to report pain without being asked $(29,47,48)$. Moreover, children's reports of pain have been dismissed as invalid or modified by health personnel in light of the child's temperament and/or behaviour at the time of the report (4953). The cues that children give are often not recognized as indicators of pain: conversely, the indexes used by clinicians 
as indicators of children's pain often do not reflect the actual pain experience $(35,40,48,54-58)$.

The complexity of correctly recognizing and interpreting pain as the first step to effective management has spurred the quest for valid, reliable and practical tools for clinical use. Several such tools are available. Using developmentally appropriate approaches for targeted age groups, a myriad of pain assessment tools have been developed and tested $(14,44,59-68)$. Mathews et al (63) noted, "ironically, in response to doubts that pain can be measured in children, intensity measures ... have been more thoroughly validated than those of adult pain. Measurement ... has become increasingly sophisticated". Although several assessment tools are now considered practical, valid and reliable for children three years of age or older, no one tool has proved to be clearly superior for use across all types of pain, age groups and clinical settings $(14,23,61,68,69)$. Several challenges remain: establishing tools that are consistently reliable, valid and clinically practical for the assessment of pain in young children, including premature and full term infants; developing tools for children with neurological disabilities and for children with chronic or recurrent pain; and identifying a tool or combination of tools that would provide a comprehensive assessment beyond the identification of pain and/or measurement of its intensity.

\section{Children's reactions to pain}

Much research has focused on the reaction of children to pain. The findings have dramatic implications for children's care. First, it is recognized that children self-initiate both overt and subtle behaviours to try to prevent or alleviate pain $(34,58,70,71)$, more so than had been recognized previously (72). It is further recognized that abilities for expressing pain vary with developmental sophistication $(40,47)$, moving from general to specific body movements; from the withdrawal of an affected part, to active avoidance of pain and then to focused coping strategies; and from behavioural to verbal expressions of pain. Hester (46) documented a decrease in crying behaviour as verbal ability increased among infants and toddlers. Moreover, Stevens et al (73) found that most premature infants do not cry audibly during painful events. These latter findings are especially noteworthy because crying is one of the primary behavioural indicators that nurses use to identify pain among very young children (50,74-76); as a result, the absence of crying may be misinterpreted as an absence of pain.

Second, many factors have been identified as affecting a child's reaction to pain. These factors include childspecific characteristics such as temperament, coping strategies and past experience with pain, as well as factors in the child's environment such as the type of injury or required procedure, perceptions of other individuals' responses to the injury, procedure or incurred pain, and enviromental stimuli $(21,40,69)$. Moreover, these factors may affect a child's learning about pain and the way that the child deals with pain in the future $(21,36,40,41,77,78)$.
Third, researchers recognize that children's reactions to chronic pain or repeated painful procedures are different from reactions to acute or short term pain. After observing and interviewing children undergoing repeated procedures, Wong and Baker (68) concluded that children do not become accustomed to pain.

Fourth, a child's perception of and reaction to pain are individualized, thus, further complicating the challenge of valid assessment. No one set of behaviours or vocalizations has been identified as being specific to pain (47), nor can it be assumed that the amount of behavioural upset directly relates to a child's level of pain (69). Assessment methods that solely rely on a child's behavioural cues as indicators of his or her pain may, therefore, never be sensitive enough for generalized clinical use.

Fifth, some of the behaviours that children use to cope with pain may provide a distraction or a focused concentration away from the pain. During such behaviours, children may not look like they are in pain $(49,50,58,77,79)$. Some children report that such behaviours avoid the negative consequences of pain; by not showing pain, the child may avoid injections, examinations or imposed activity restrictions $(50,80)$.

Sixth, children may believe that pain is intrinsic to their condition. Several studies have documented children's beliefs that health care professionals know how they are feeling and care for them accordingly, providing available pain relief strategies without being asked; therefore, when pain is experienced, it must be an unavoidable part of their condition or treatment $(29,51,81)$. Children may not realize that there are alternatives to enduring pain or that they have to tell the doctor or nurse about their pain to access these alternatives $(29,82)$. Similar beliefs have been reported by parents $(2,29)$ and in adult population groups (55).

Lastly, it is well known that children fear needles and find them painful. This knowledge has been repeatedly documented in interview studies of hospitalized children $(17,29,46,68,83)$. Procedures involving needles have been reported to be the worst part of illness (17). Furthermore, Steward (17) found that younger children (younger than nine years of age) have more pain from needles than older children; he suggested that this may be due to the inability to modulate the pain perception with the knowledge that the injection pain will end, and to make the connection between the injected medication (added pain) and the reason it was given (pain in another area of the body).

\section{Strategies and technologies for postoperative pain}

Berde (12) contended: "The inadequate treatment of postoperative pain is particularly unfortunate because for the overwhelming majority of children, analgesia could be provided with ease and a very wide margin of safety". Much progress has been made in refining pharmacological strategies for pain management, both in knowledge of effective medications and routes of administration. Several overviews that outline the most effective medications, criteria for selection, titration 
of dosages and indications for choice of routes are available $(12,21,80,83-92)$. Combined therapy, using more than one medication and/or route, is often recommended to maximize the beneficial effects of each medication and/or route $(92,93)$. Perhaps because of the variety of both medications and technologies now available for use with children, and the potential complexity of regimens, clinicians are reminded to know well both the medications and the technologies that they use, and to 'do the simple things well' before automatically choosing more complex technologies and/or medication combinations $(94,95)$. Clinicians are also reminded that, while pharmacological strategies will always be the mainstay of pain management, nonpharmacological strategies are available and are an important adjuvant therapy in a comprehensive approach to pain management $(23,41,46,89,96$ 101 ), particularly in complex or long term pain patterns.

Clinical research has documented the effectiveness of continuous rather than intermittent infusions of analgesics for acute pain $(12,80,85,96,102)$, the use of patient-controlled analgesia whenever possible (12,96,103-107), blocks (108) and epidural analgesia $(12,109,110)$. Alternative routes, such as transcutaneous, transmucosal and intranasal administration of medications, are also being explored and show promise $(12,83,91,96)$.

Consistently in the literature, authors document the inappropriateness of intramuscular injections in pediatric care, particularly for pain management, and have advocated the elimination of such injections $(12,21,70,80,93,105,106,111$ $115)$. Giving medications orally whenever possible, and by intravenous or epidural routes when the oral route is not feasible, is strongly advocated. Similarly, authors stated that pro re nata (PRN) orders for analgesics are ineffective in practice, particularly in postoperative or procedural care $(34,41,86,96,102,107,109,116-118)$. In practice, $P R N$ is interpreted as 'only when necessary', and rather than facilitating individualized pain management, PRN orders actually impede a basic medication regimen for pain. A protocol for 'around the clock' analgesic administration, with PRN interventions for breakthrough pain, is recommended $(34,41,86$, 96,102,107,109,116-118).

Other recommendations include the concurrent use of opioid and nonopioid analgesics during a child's pain management $(22,92,94,113,115)$, and the use of the 'pain ladder' approach, a systematic choice of analgesics from a specified sequence to titrate medications to each child's response $(83,86,92,115,119)$ to pain. The need for a 'pre-emptive' pain management approach, which begins preoperatively by guiding anesthetic and intraoperative analgesic selection, and follows each child's postoperative course, is strongly emphasized; similar pre-emptive plans are advocated for procedural, cancer, palliative and chronic pain conditions $(12,34,88,96,105,115,120)$.

\section{THE PROBLEM REMAINS}

Despite the surge of new knowledge over the past decade, the clinical care of children's pain remains inadequate. Cohen (96) stated that "children fear the prospect of pain following surgery. Unfortunately, research in this area supports their fears". Numerous studies document the continued undermedication and periodic overmedication of children in comparison with recommended postoperative protocols (35, $57,106,114,117,121-129)$.

The effect of this pattern of dosing and administration becomes significant only in light of strong evidence that children are in pain postoperatively. Of studies published since 1990 (theoretically reflecting the documentation of present practice), a few examples illustrate the persistent and widespread problem.

- Hester (46) referred to one of her own studies in which only $7 \%$ of children surveyed $(n=72)$ reported no pain on their first postoperative day.

- Romsing and Walther-Larsen (128) found that 29\% of the parents in their study (nine of 31) reported that their child had experienced "unbearable severe pain" during the $24 \mathrm{~h}$ following surgery; nine of the 16 children interviewed on the second postoperative day reported that they had pain.

- Gillies et al (124) reported that, among a group of adolescents, $80 \%$ (12 of 15 ) had postoperative pain, "but their needs were recognized inadequately and the management of their pain was inconsistent". In the follow-up to this study, $91 \%$ of 351 adolescents reported pain on the first day after surgery; $50 \%$ of the group reported that their pain on day 1 was moderate to severe (130). On day 3, approximately $75 \%$ of the group continued to have pain and $35 \%$ of the children rated their pain as moderate to severe. When charts were reviewed, there was little documentation of the presence or absence of pain.

- Alex and Ritchie (81) asked 24 children (ages seven to 11 years) to rate their pain three times on their first postoperative day. Times were chosen randomly for each child. On 25 of 72 assessments, the children reported moderate to severe pain; half of these reports of pain occurred within $4 \mathrm{~h}$ of having received an analgesic.

- In a study focusing on analgesic administration patterns, Tesler and colleagues (129) documented that children ( $n=131$, ages eight to 17 years) reported moderate to severe postoperative pain for as long as five days after surgery. The researchers reported that two-thirds of the children were beyond analgesic action when pain was assessed.

- Among 23 children recovering from orthopedic surgery, Kart and colleagues (126) found that $70 \%$ of the children reported the experience of at least one episode of pain in 
the first three days following their surgeries, and $26 \%$ of the children reported 'the worst pain [they] could imagine'.

- In his review of the literature, Steward (17) stated that as many as $87 \%$ of children reported that they had postoperative pain, with $19 \%$ rating their 'usual pain' as severe.

- Finally, and perhaps most importantly, Cummings and colleagues (123) reported that $23 \%$ of children in their study stated that they had received no help during their usual or worst pain experiences.

The problem of an ineffective approach to postoperative pain relief extends beyond the inpatient unit $(120,130)$. Finley and colleagues (130) asked parents to record their assessments of their child's pain and their administration of analgesics for the three days following a 'day surgery' procedure. Parents of 115 of 189 (61\%) children reported that their child had significant pain (a rating of 4 or greater on a 10point visual analogue scale) one day after the surgery. The amount of medication administered on day 1 was not reported. Of children who were judged to be in significant pain, $60.2 \%$ and $61.7 \%$ were given three or fewer doses of medication on days 2 and 3, respectively. With few exceptions, the parents reported that they had not been taught or encouraged to use analgesics to treat pain after the child's discharge. Only $17.5 \%$ of the parents remembered receiving specific instructions for regular medication use.

This lack of instruction is not assumed to be deliberate decisions of health care professionals to inflict or increase pain. Studies document that many caregivers recognize children's pain and report their intent to alleviate that pain, yet actual interventions fall far short of that intention (111,131,132-134). Four general issues have been presented to account for this discrepancy: nonprioritization of pain relief, limited clinical information or resources in hospitals, the persistence of misinformation and attitudes that counteract adequate pain relief.

\section{Nonprioritization of pain relief}

Nonprioritization of pain relief has occurred in two ways. First, until fairly recently, institutions did not actively prioritize the treatment of children's pain within their mandates; many institutions still do not do so. Consequently, in these settings, there are no standards or protocols for the assessment and the management of pain $(7,8,47)$, and there are no institutional incentives or supports for any such initiatives that are attempted within an institution (6). Second, the multidisciplinary nature of effective pain management has meant that when no formal policy has been developed for universal implementation within an institution, no one group has taken responsibility for pain relief, the scope of the problem is usually unrecognized, pain is not communicated among disciplines, and initiatives are sporadic and fragmented $(6,31,134)$.

\section{Limited clinical information or resources}

Schechter et al (8) noted that much of the literature about children's pain, its assessment and management has been published in research journals or presented at conferences; often, these media are not readily available to, read by or attended by staff who provide care. Although this situation has changed in recent years as efforts have been made to make the knowledge of children's pain more clinically usable, the process of dissemination continues to be slow. As well, the main resource textbooks that are used to teach students and staff usually do not include sections on children's pain $(8,89)$. Although this situation has also changed in the past five to seven years, recent textbooks (which reflect the tremendous increase in knowledge of children's pain, particularly infant's pain, and clinical strategies to assess and manage that pain) may not be readily available or accessible in clinical units.

The availability of staff resources such as trained personnel, staff shortages and/or limited access to equipment, such as pumps for patient-controlled analgesia or monitoring equipment, may also present barriers to effective pain intervention within an agency $(46,96,111,135,136)$.

\section{Persistence of misinformation}

Ongoing misinformation about children's pain is widely considered to be the primary barrier to effective care. Myths and misconceptions, such as children (especially very young children) not being able to feel pain, the impossibility of accurate assessment of children's pain and the dangers of administering analgesics to children continue $(29,32,35,48,83,137,138)$. Researchers have documented that many physicians and nurses have weak or inaccurate knowledge bases regarding the pathophysiology and the postoperative effects of pain, the pharmacology of analgesics, the actual risk of complications and effective strategies to assess or manage pain $(7,25,54,85$, $129,130,139-142)$. Some caregivers assume that within their institution there are no alternatives to the practices and policies in place, so they continue to work within a system that they recognize as being inadequate $(143,144)$.

Schechter et al (8) contended, and other researchers $(48,111)$ agree, that until recently there has been a general lack of basic education of physicians and nurses about children's pain. As a result, young health care professionals have learned from the practices of their institutions and preceptors, leading to the perpetuation of old knowledge and techniques, old myths and fears.

\section{Attitudes that counteract adequate pain relief}

Attitudes of staff about the meaning of pain and its effects determine the staff philosophy and policy regarding intervention; ie, if pain is viewed to be important for learning coping skills, a spiritual challenge or an expected part of childhood, intervention is less likely, even when pain is recognized $(8,52,132,145,146)$. Similarly, clinical decisions and interventions differ depending on a caregiver's goal for pain relief: relieving pain only enough to allow for subsequent care activities and procedures; relieving pain enough for an activ- 
ity or a rest level that approximates the child's normal pattern; or a total resolution of pain $(41,54,125,147)$.

The persistence of myths and entrenched attitudes that have perpetuated the under-recognition and undertreatment of children's pain seems incredible in light of the overwhelming evidence about children's pain and strategies available to manage pain. Although misinformation is a part of the problem, providing education has not automatically resolved the issue. Cassidy and Walco (145) suggest that the entrenchment of myths and misinformation about children's pain in the face of refuting evidence is based on one or more of three ethical justifications: revisionist (it is not that bad), comparative (it is not the worst) and pragmatic (it may produce something better). Although such justifications have merit in other situations, in the case of children's pain, they are only self-protective; the alternative - that children have been suffering directly or indirectly because of institutional or personal nonrecognition and nonresponse to their pain - is very difficult to acknowledge.

Pasero and colleagues (6) stated that institutional and personal entrenchment in traditional practices and beliefs presents the largest challenge to implementing change within institutions, even if standards, protocols and resources are available. Moreover, they suggest that effective change will not occur unless initiatives directly address the underlying fears and concerns on which the entrenchment is based, and that mechanisms to avoid or address the feared consequences be specifically and clearly addressed in standards, policies and protocols developed.

\section{A MANDATE FOR CHANGE}

Health professionals have an ethical imperative to treat children's pain $(132,145,148,149)$. Copp $(132)$ contended that, from an ethical perspective, not attending to a patient's pain may cause harm through negligence. Although total and continuous relief of every child's pain may be an unattainable goal, it is imperative that health professionals and their respective clinical agencies plan and implement a comprehensive approach to address and alleviate children's pain so that pain is avoided whenever possible, and any unanticipated or breakthrough pain experienced is kept to a mininum level.

The backgrounds of the authors of the literature reviewed in the present paper document that the call for change is coming from all sectors, including researchers and clinicians, nurses, physicians, pharmacists and physiotherapists. Efforts are being made nationally and internationally to address this call. The United States Department of Health and Human Services has published guidelines that specifically focus on the relief of children's postoperative pain (70). To date, these standards have been available free of charge to clinical agencies. The World Health Organization (WHO) has recently distributed its standards for pediatric cancer and palliative pain care, which outline specific principles and guidelines for comprehensive care (115). Even more recently, committees in the United States and Canada have joined forces to publish a statement on the "Prevention and management of pain and stress in the neonate" (19) - a very exciting sign of progress in recognizing and addressing pain in very young children.

Although the WHO guidelines for cancer and palliative care were developed in response to one type of pain, the development team stressed that the principles outlined are applicable to all types of children's pain and management of the pain $(115,147)$. Four guiding phrases are presented in the document as keystones for clinicians: 'by the ladder' using the pain ladder to choose analgesics systematically (type, dose and frequency) as indicated during the length of a child's care; 'by the clock' - either continuously or at regular intervals, potentiating a more consistent level of analgesic and aiming to prevent pain rather than to treat the pain only when it becomes severe; 'by the appropriate route' using the simplest, most effective and least painful route; and 'by the child'-planning and implementing a pain protocol for the child as determined by the child's requests and reactions.

These four principles are consistent with recommendations outlined in all of the literature reviewed. Moreover, huge strides in children's care could immediately be made by clinicians integrating the four guiding principles in their own practices within existing policies. However, the mandate for change is larger still. For a real change in the alleviation of children's pain, a focused, coordinated and multidisciplinary effort is needed. Specific recommendations are as follows.

- Institutions must make children's pain a priority by establishing standards and policies for the assessment, documentation and management of pediatric pain, and ensuring that the clinical care of children reflects that priority $(6,7,35,44,47,50,52,55,70,80,86,102,116,123$, $136,140,141,147,150,151)$. Incentives for staff, unit or institutional initiatives will foster both creativity and motivation in planning and implementing change. Resources directly oriented to clinicians and clinical agencies are available to assist in this process (89). Recent progress in this area must be recognized (152). Many institutions are making children's pain a priority and have or are developing policies and protocols to guide clinicians in their assessment and management of children's pain (151,153-156). Avenues are available to share this information and to consult between institutions and colleagues as challenges arise $(157,158)$. Furthermore, organizational structures and cultures that "support or mitigate practices and implementation of change" within clinical units or organizations as a whole are now being investigated (135), partly in response to accreditation mandates for quality control and outcome measurement in relation to pain care. This progress is a tremendous beginning, but only a beginning, because protocols developed must be accepted and implemented by those directly caring for children, and many institutions and organizations have not yet begun to consider children's pain as being a priority. 
- Institutional and personal barriers to the implementation of a responsive and comprehensive approach to children's pain must be identified, directly addressed and alleviated. Moreover, the safeguards needed to alleviate barriers must be reflected in standards and protocols developed (6).

- Education programs must be implemented for clinicians about children's pain, its pathology, strategies to identify pain and choices for its management (both pharmacological and nonpharmacological) $(47,48,96$, $101,103,118,121,141,144,149,159,160)$. Foster (118) contended that, even if no other change is made, education will potentiate improvements in the assessment and management of children's pain. Education, however, must be considered only as one essential step in implementing change; 'action steps' are required to implement the new knowledge into clinical practice $(6,141,161,162)$.

- Parents, often the forgotten resource in pediatric care, must be included in their child's pain care, and taught how to identify and alleviate their child's pain in hospital, and as needed after discharge $(12,29,40,50,70$, $71,111,120,131,143,160,163-165)$. Parents also should be included, when possible, on planning teams as new initiatives are developed (6).

- Identification of a multidisciplinary pain team is strongly recommended $(6,93,105,120,128,166-168)$. It is important that the team be multidisciplinary, reflecting the different partners in comprehensive pain care, but also that members of the team work as interdisciplinary partners as well (6). The role(s) of this team will be determined by staff and agency needs. These roles may include consulting about each child's regimen or for problematic situations only; designing and overseeing the implementation of institutional or unit-specific initiatives; organizing educational programs for staff regarding children's pain, or inservices as new initiatives are planned and introduced; and/or generating ideas and avenues for change.

- A 'pre-emptive' approach is advocated by establishing a coordinated and individualized plan for pain care from the preoperative assessments to postoperative recovery, from diagnosis to resolution of pain syndromes, and among agencies, as applicable, to each child $(12,70$, $96,105,119)$. The WHO guidelines (115) stress that this comprehensive approach must also be proactive in addressing side effects that may occur in pharmacological pain management therapy; side effects should be anticipated, and interventions to minimize their occurrence or alleviate them as soon as they occur must be a standard part of each child's outlined protocol.

\section{SUMMARY AND CONCLUSIONS}

A history of inadequate management of children's pain has been documented. Before 1985, little research attention was focused on children's pain, its effects, identification or treatment. Expectedly, studies of clinical practice at that time reflected both a lack of attention and a lack of knowledge about children's pain. Since that time, however, a multitude of resources outlining new knowledge about children's pain, as well as effective strategies for assessing and treating children's pain have become available. Unfortunately, despite progress in many venues, a gap remains between the knowledge base established and the implementation of that knowledge in the clinical care of children. The time to close that gap is now.

Many of the needed changes are, in fact, small adjustments to care that are already being provided. In establishing clinical practice standards for institutions, health professionals, as individuals and as groups, can systematically and regularly assess and document children's pain; become more knowledgeable about pain relief regimens being used in respective institutions, and how these regimens can be maximized within individual practices and disciplines; facilitate communication among disciplines involved in each child's care; and, as indicated, organize policy changes to ensure an ongoing, comprehensive approach to children's pain.

\section{REFERENCES}

1. Swafford LI, Allan D. Pain relief in the pediatric patient. Med Clin North Am 1968;52:131-5.

2. Eland JM, Anderson JE. The experience of pain in children. In: Jacox A, ed. Pain: A Sourcebook for Nurses and Other Health Professionals. Boston: Little \& Brown, 1977:453-73.

3. Beyer JE, DeGood DE, Ashley LC, Russell GA. Patterns of postoperative analgesic use with adults and children following cardiac surgery. Pain 1983;17:71-81.

4. Mather L, Mackie J. The incidence of postoperative pain in children. Pain 1983;15:271-82.

5. Larsson BA. The measurement of paediatric pain. Acta Paediatr 1999;88:115-17

6. Pasero C, Gordon G, McCaffery M, Ferrell BR. Building institutional commitment to improving pain management. In: McCaffery M, Pasero C, eds. Pain: Clinical Manual. St Louis: Mosby Inc, 1999:711-44.

7. Ready LB, Edwards WT, eds. Management of Acute Pain: A Practical Guide. Seattle: IASP Publications, 1992.

8. Schechter NL, Berde CB, Yaster M. Pain in infants, children and adolescents: An overview. In: Schechter NL, Berde CB, Yaster M, eds. Pain in Infants, Children and Adolescents. Baltimore: Williams \& Wilkins, 1993:3-9.

9. Anand S. Supra spinal biological measurement. International Forum on Pediatric Pain: Measurement of Children's Pain. Nova Scotia, October 5, 1996.

10. Anand KJS, Hickey PR. Pain and its effects in the human neonate and fetus. N Engl J Med 1987;317:1321-9.

11. Andrews K, Fitzgerald M. Biological barriers to paediatric pain management. Clin J Pain 1997;13:138-43.

12. Berde CB. Pediatric postoperative pain management. Pediatr Clin North Am 1989;36:921-40. 
13. Fitzgerald M, Anand KJ. Developmental neuroanatomy and neurophysiology of pain. In: Schechter NL, Berde CB, Yaster M, eds. Pain in Infants, Children and Adolescents. Baltimore: Williams \& Wilkins, 1993:11-31.

14. McGrath PJ. Paediatric pain: A good start. Pain 1990;41:253-4.

15. Porter FL, Grunau RE, Anand KJS. Long-term effects of pain in infants. J Dev Behav Pediatr 1999;20:253-61.

16. Stevens B, Koren G. Evidence-based pain management for infants. Curr Opin Pediatr 1998;10:203-7.

17. Steward DJ. Introduction to "Management of childhood pain: New approaches to procedure related pain". J Pediatr 1993;22:S1.

18. Wolf AR. Pain, nociception and the developing infant. Paediatr Anaesth 1999;9:7-17.

19. Prevention and management of pain and stress in the neonate. Joint statement of the Canadian Paediatric Society and the American Academy of Pediatrics. Paediatr Child Health 2000;5:31-8.

20. Fitzgerald M. Spinal and peripheral biological measurement. International Forum on Pediatric Pain: Measurement of Children's Pain. Nova Scotia, October 5, 1996.

21. Haberkern CM, Tyler DC, Krane EJ. Postoperative pain management in children. Mt Sinai J Med 1991;58:247-56.

22. Lau N. Pediatric pain management (Part I). J Pediatr Health Care 1992;6:87-92.

23. McGrath PJ. Annotation: Aspects of pain in children and adolescents. J Child Psychol Psychiatry 1995;36:717-30.

24. Van Keuren K, Eland JA. Perioperative pain management in children. Nurs Clin North Am 1997;32:31-44.

25. Schechter NL. The undertreatment of pain in children: an overview. Pediatr Clin North Am 1989;36:781-94.

26. Kart T, Christrup L, Rasmussen M. Recommended use of morphine in neonates and children based on a literature review: Part 1 Pharmacokinetics. Paediatr Anesth 1997;7:5-11.

27. Kart T, Christrup L, Rasmussen M. Recommended use of morphine in neonates and children based on a literature review: Part 2 - Clinical use. Paediatr Anesth 1997;7:93-101.

28. Koren G, Jacobsen S. Developmental considerations in the clinical pharmacology of analgesics. In: Schechter NL, Berde CB, Yaster M, eds. Pain in Infants, Children and Adolescents. Baltimore: Williams \& Wilkins, 1993:33-8.

29. McCaffery M, Beebe A. Pain in children: Special considerations. In: McCaffery M, Beebe A, eds. Pain: Clinical Manual for Nursing Practice. St Louis: CV Mosby, 1989:264-306.

30. Clark AG. Recent developments in postoperative analgesia. Pain Manage Newsl 1990;3:1-2.

31. Rogers MC. Do the right thing: pain relief in infants and children. N Engl J Med 1992;326:55-6.

32. Stevens B. Pain in infants. In: McCaffery M, Pasero C, eds. Pain: Clinical Manual. St Louis: Mosby Inc, 1999:626-73.

33. Perreault T, Fraser Askin D, Liskin R, et al. Pain in the neonate. Pediatr Child Health 1997;2:201-9.

34. Acute Pain Management Guideline Panel, United States Department of Health and Human Services. Acute Pain Management: Operative or Medical Procedures and Trauma. Clinical Practice Guideline. AHCPR no 92-0032. Rockville: Agency for Health Care Policy and Research, 1992.

35. Ross RS, Bush JP, Crummette BD. Factors affecting nurses' decisions to administer PRN analgesic medication to children after surgery: An analog investigation. J Pediatr Psychol 1999;16:151-67.

36. Ornstein PA, Manning EL, Pelphrey KA. Children's memory of pain. J Dev Behav Pediatr 1999;20:262-77.

37. Taddio A, Katz J, Ilersich AL, Koren G. Effect of neonatal circumcision on pain response during subsequent routine vaccination. Lancet 1997;349:599-603.

38. Kotiniemi LH, Ryhanen PT, Moilanen IK. Behavioral changes in children following day-case surgery: a 4-week follow-up of 551 children. Anaesthesia 1997;52:970-6.
39. Weisman SJ, Bernstein B, Schechter NL. Consequences of inadequate analesia during painful procedures in children. Arch Pediatr Adolesc Med 1998;152:147-9.

40. Zeltzer LK, Bush JP, Chen E, Riveral A. A psychobiologic approach to pediatric pain: Part I. History, physiology and assessment strategies. Curr Probl Pediatr 1997;27:225-58.

41. Zeltzer LK, Bush JP, Chen E, Riveral A. A psychobiologic approach to pediatric pain: Part II. Prevention and treatment. Curr Probl Pediatr 1997;27:264-84.

42. Pain terms: A list with definitions and notes on usage. Recommended by the IASP Subcommittee on Taxonomy. Pain 1979;6:249.

43. Merskey H. The definition of pain. Eur J Psychol 1991;6:153-9.

44. Ross DM, Ross SA. Assessment of pediatric pain: An overview. Issues Compr Pediatr Nurs 1988;11:73-91.

45. Anand KJS, Craig KD. New perspectives on the definition of pain. Lett Pain 1996;67:3-6.

46. Hester NO. Pain in children. Rec Adv Nurs Res 1993;11:105-42.

47. Betz CL, Hunsberger M, Wright S. Family-Centered Nursing Care of Children, 2nd edn. Philadelphia: WB Saunders Company, 1994.

48. Gillies MJ. Post-operative pain in children: a review of the literature. J Clin Nurs 1993;2:5-10.

49. Abu Saad HH, Hamers JPH. Decision making and paediatric pain: A review. J Pediatr Nurs 1997;26:946-52.

50. McCaffery M, Wong D. Nursing interventions for pain control in children. In: Schechter NL, Berde CB, Yaster M, eds. Pain in Infants, Children and Adolescents. Baltimore: Williams \& Wilkins, 1993:395-16.

51. McGrath PJ, Frager G. Psychological barriers to optimal pain management in infants and children. Clin J Pain 1996;12:135-41.

52. Scott I. Nurses' attitudes to pain control and use of pain assessment scales. Br J Nurs 1992;1:595-9.

53. Wallace MR. Temperament: A variable in children's pain management. Pediatr Nurs 1989;15:118-21.

54. Burokas L. Factors affecting nurses' decisions to medicate pediatric patients after surgery. Heart Lung 1985;14:373-9.

55. Carr ECJ. Postoperative pain: Patients' expectations and experiences. J Adv Nurs 1990;15:89-100.

56. Hamers JPH, Abu Saad HH, van den Hout MA, Halfens RJG, Kester ADM. The influence of children's vocal expressions, age, medical diagnosis and information obtained from parents on nurses' pain assessments and decisions regarding interventions. Pain 1996;65:53-61.

57. Hamers JPH, Abu Saad HH, van den Hout MA, Halfens RJG. Are children given insufficient pain relieving medication postoperatively? J Adv Nurs 1998;27:37-44.

58. Tesler MD, Holzeman WL, Savedra MC. Pain behaviors: Post surgical responses of children and adolescents. J Pediatr Nurs 1998;13:41-7.

59. Bieri D, Reeve RA, Champion GD, Addicoat L, Ziegler JB. The Faces Pain Scale for the self-assessment of the severity of pain experienced by children: development, initial validation and preliminary investigation for ratio scale properties. Pain 1990;41:139-50.

60. Chambers CT, Giesbrecht K, Craig KD, Bennett SM, Huntsman E. A comparison of faces scales for the measurement of pediatric pain: children's and parents ratings. Pain 1999;83:25-35.

61. Finley GA, McGrath PJ, eds. Measurement of Pain in Infants and Children: Progress in Pain Research and Management, vol 10. Seattle: IASP Press, 1998

62. Grunau RE, Oberlander T, Holsti L, Whitfield MF. Bedside application of the neonatal facial coding system in pain assessment of premature neonates. Pain 1998;76:277-86.

63. Mathews JR, McGrath PJ, Pigeon H. Assessment and measurement of pain in children. In: Schechter NL, Berde CB, Yaster M, eds. Pain in Infants, Children and Adolescents. Baltimore: Williams \& Wilkins, 1993:97-111.

64. McGrath PA, Seifert CE, Speechley KN, Booth JC, Stitt L, Gibson MC. A new scale for assessing children's pain: An initial validation study. Pain 1996;64:435-43.

65. Porter F. Pain assessment in children: Infants. In: Schechter NL, 
Berde CB, Yaster M, eds. Pain in Infants, Children and Adolescents. Baltimore: Williams \& Wilkins, 1993:87-96.

66. Savedra MC, Holzemer WL, Tesler MD, Wilkie DJ. Assessment of postoperative pain in children and adolescents using the Adolescent Pediatric Pain Tool. Nurs Res 1993;42:5-9.

67. Stevens B, Johnston CC, Petryshen P, Taddio A. The premature infant pain profile. Clin J Pain. 1996;12:13-22.

68. Wong DL, Baker CM. Pain in children: Comparison of assessment scales. Pediatr Nurs 1988;14:9-17.

69. McGrath PA. Pain in the pediatric patient: Practical aspects of assessment. Pediatr Ann 1995;24:126-33,137-8.

70. Acute Pain Management Guideline Panel, United States Department of Health and Human Services. Acute Pain Management in Infants, Children and Adolescents: Operative or Medical Procedures. AHCPR no 92-0020. Rockville: Agency for Health Care Policy and Research, 1992.

71. Woodgate R, Kristjansen LJ. "Getting better from my hurts": Toward a model of the young child's pain experience. J Pediatr Nurs 1996;11:233-42.

72. Woodgate R, Kristjansen LJ. Young children's behavioral responses to acute pain: Strategies for getting better. J Adv Nurs 1995;22:242-9.

73. Stevens BJ, Johnston CC, Horton L. Factors that influence the behavioral pain responses of preterm infants. Pain 1994;9:101-9.

74. Hamers JPH, Abu-Saad HH, Halfens RJG, Schumacher JNM. Factors influencing nurses' pain assessment and interventions in children. J Adv Nurs 1994;20:853-60.

75. Miller D. Comparisons of pain ratings from postoperative children, their mothers and their nurses. Pediatr Nurs 1996;22:145-9.

76. Powers DM. Ratings of pain from postoperative children and their nurses. Nurs Pap 1987;19:49-58.

77. McCaffery M, Pasero C. Assessment: Underlying complexities, misconceptions and practical tools. In: McCaffery M, Pasero C, eds. Pain: Clinical Manual. St Louis: Mosby Inc, 1999:35-102.

78. Palermo TM. Impact of recurrent and chronic pain on child and family functioning: A critical review of the literature. J Dev Behav Pediatr 2000;21:58-69.

79. Tyler DC, Tu A, Douthit J, Chapman CR. Toward validation of pain measurement tools for children: A pilot study. Pain 1993;52:301-9.

80. Rice LJ. Pain management in children. Can J Anaesth 1996;43:R155-8.

81. Alex MR, Ritchie JA. School-aged children's interpretation of their experience with acute surgical pain. J Pediatr Nurs 1992;7:171-80.

82. Kachoyeanos MK, Zollo MB. Ethics in pain management of infants and children. MCN Am J Matern Child Nurs 1995;20:142-7.

83. Waters L. Pharmacologic strategies for managing pain in children. Orthop Nurs 1992;11:34-40.

84. Birmingham PK. Recent advances in acute pain management. Curr Probl Pediatr 1995;25:99-112.

85. Choonara IA. Pain relief. Arch Dis Child 1989;64:1101-2.

86. Collier J, ed. Managing pain in children. Drug Ther Bull 1995;33:41-4.

87. Gaukroger PB. Pediatric analgesia: Which drug? Which dose? Drugs 1991;41:52-9.

88. Krauss B, Green SM. Sedation and analgesia for procedures in children. N Engl J Med 2000;342:938-45.

89. McCaffery M, Pasero C, eds. Pain: Clinical Manual. St Louis: Mosby Inc, 1999:103-427.

90. McKenzie I, Gaukroger PB, Ragg P, Brown T. Manual of Acute Pain Management in Children. New York: Churchill Livingstone, 1997.

91. Litman RS. Recent trends in the management of pain during medical procedures in children. Pediatr Ann 1995;24:158-63.

92. Tobias JD. Postoperative pain management. Pediatr Ann 1997;26:490-500.

93. Howard R. Post-operative pain relief. Matern Child Health 1994;19:66-71.

94. Morton NS. Prevention and control of pain in children. Br J Anaesth 1999;83:118-29.
95. Zacharias M, Watts D. Pain relief in children. BMJ 1998;316:1552.

96. Cohen D. Management of postoperative pain in children. In: Schechter NL, Berde CB, Yaster M, eds. Pain in Infants, Children and Adolescents. Baltimore: Williams \& Wilkins, 1993:357-83.

97. Goldman A. Pain management. Arch Dis Child 1992;68:423-5.

98. Jonas D, Day A, Binns F. Management of paediatric pain 1: non-drug approaches. Community Nurse 1998:4:44-5.

99. Kazak AE, Penati B, Brophy P, Himelstein B. Pharmacologic and psychologic interventions for procedural pain. Pediatrics 1998;102:59-66.

100. Pederson C. Nonpharmacologic interventions to manage children's pain: Immediate and short term effects of a continuing education program. J Contin Educ Nurs 1996;27:131-40.

101. Vessey JA, Carlson KL. Nonpharmacological interventions to use with children in pain. Issues Compr Pediatr Nurs 1996;19:169-82.

102. Woodin LM. Cutting postop pain. Regist Nurse 1993;56:26-34.

103. Clarke HF, Derrick L, Eivemark J, et al. Patient-controlled analgesia. Nurs BC 1995;27:15-16.

104. Cohen DG. Patient-controlled analgesia use in children and adolescents. J Pediatr Oncol Nurs 1992;9:68. (Abst)

105. Howard R. Preoperative and postoperative pain control. Arch Dis Child 1993;69:699-703.

106. McCready M, MacDavitt K, O’Sullivan KK. Children and pain: Easing the hurt. Orthop Nurs 1991;10:33-42.

107. Webb CJ, Stergios DA, Rodgers BM. Patient controlled analgesia as postoperative pain treatment for children. J Pediatr Nurs 1989;4:162-71.

108. Broadman LM. Blocks and other techniques pediatric surgeons can employ to reduce postoperative pain in pediatric patients. Semin Pediatr Surg 1999;8:30-3.

109. Jones MD, Aronsson DD, Harkins JM, Smail DF, Haugh LD. Epidural analgesia for postoperative pain control in children. J Pediatr Orthop 1998;18:492-6.

110. Ready LB, Loper KA, Nessly M, Wild L. Postoperative epidural morphine is safe on surgical wards. Anesthesiology 1991;75:452-546.

111. Broome ME, Richtsmeier A, Maikler V, Alexander M. Pediatric pain practices: A national survey of health professionals. J Pain Symptom Manage 1996;11:312-20.

112. Hendrickson M, Myre L, Johnson DG, Matlak ME, Black RE, Sullivan JJ. Post-operative analgesia in children in children: A prospective study of study of intermittent intramuscular injection versus continuous intravenous infusion of morphine. J Pediatr Surg 1990;25:185-91.

113. Lau N. Pediatric pain management (Part II). J Pediatr Health Care 1992;6:214-9.

114. Maikler VE. Pharmacologic pain management in children: A review of intervention research. J Pediatr Nurs 1998;13:3-14.

115. World Health Organization. Cancer pain relief and palliative care in children. Geneva: World Health Organization,1998.

116. Atkinson L. Pain management for children and infants. Contemp Nurs 1996;5:64-70

117. Bush JP, Holmbeck GN, Cockrell JL. Patterns of PRN analgesic drug administration in children following elective surgery. J Pediatr Psychol 1989;14:433-48.

118. Foster RL. Pain management. J Soc Pediatr Nurs 1996;1:93-4.

119. Carr DB, Jacox AK. Acute pain management in infants, children and adolescents: operative and medical procedures. Can J Pediatr 1997;6:391-7.

120. Wolf AR. Tears at bedtime: a pitfall of extending paedriatric day-care surgery without extending analgesia. Br J Anaesth 1999;82:319-20.

121. Altimer L, Norwood S, Dick MJ, Holditch-Davis D, Lawless S. Postoperative pain management in preverbal children: The prescription and administration of analgesics with and without caudal analgesia. J Pediatr Nurs 1994;9:226-32.

122. Asprey JR. Postoperative analgesic prescription and administration in a pediatric population. J Pediatr Nurs 1994;9:150-7.

123. Cummings EA, Reid GJ, Finley GA, McGrath PJ, Ritchie JA. 
Prevalence and source of pain in pediatric inpatients. Pain 1996;68:25-31.

124. Gillies MJ, Parry-Jones W, Smith L. Post-operative pain in adolescents: a pilot study. J Clin Nurs 1997;6:77-8.

125. Herr KA, Mobily PR. Interventions related to pain. Nurs Clin North Am 1992;27:347-69.

126. Kart T, Rasmussen M, Horn A, Wested L. Management of postoperative pain in children undergoing orthopaedic surgery. J Pediatr Orthop 1996;16:545-8.

127. Romsing J. Assessment of nurses' judgement for analgesic requirements of postoperative children. J Clin Pharmacol Ther 1996;21:159-63.

128. Romsing J, Walther-Larsen S. Postoperative pain in children: A survey of parents' expectations and perceptions of their children's experiences. Paediatr Anaesth 1996;6:215-8.

129. Tesler MD, Wilkie DJ, Holzemer WL, Savedra MC. Postoperative analgesics for children and adolescents: Prescription and administration. J Pain Symptom Manage 1994;9:85-95.

130. Gillies ML, Smith LN, Parry-Jones WL. Post operative pain assessment and management in adolescents. Pain 1999;79:207-15.

131. Finley GA, McGrath PJ, Forward SP, McNeill G, Fitzgerald P. Parents' management of children's pain following 'minor' surgery. Pain 1996;64:83-7.

132. Copp LA. An ethical responsibility for pain management. J Adv Nurs 1993;18:1-3.

133. McGrath P, Vair C, McGrath MJ, Unrah A, Schnurr R. Pediatric nurses' perception of pain experienced by children and adults. Nurs Pap 1984;16:34-9.

134. Porter FL, Wolf CM, Gold J, Lotsoff D, Miller LP. Pain and pain management in newborn infants: a survey of physicians and nurses. Pediatrics 1997;100:626-32.

135. Hester NO, Miller KL, Foster RL, Vojir CP. Symptom management outcomes: Do they reflect variations in the care delivery systems? Med Care 1997;35:NS69-83.

136. Jacox A, Ferrell B, Heidrich G, Hester N, Miaskowski C. A guideline for the nation: Managing acute pain. Am J Nurs 1992;92:49-55.

137. Beyer JE, Byers ML. Knowledge of pediatric pain: The state of the art. Child Health Care 1985;13:150-9.

138. Caty S, Tourigny J, Koren I. Assessment and management of children's pain in community hospitals. J Adv Nurs 1995;22:638-45.

139. Altemeier WA, York D. A pediatrician's view: “This doesn't hurt, does it, Johnny?". Pediatr Ann 1997;28:448,450-1.

140. Holder KA, Patt RB. Taming the pain monster: Pediatric postoperative pain management. Pediatr Ann 1995;24:164-8.

141. Lebovits AH, Florence I, Bathina R, Hunko V, Fox MT, Bramble CY. Pain knowledge and attitudes of healthcare providers: Practice characteristic differences. Clin J Pain 1997;13:237-43.

142. Read JV. Perceptions of nurses and physicians regarding pain management of pediatric emergency room patients. Pediatr Nurs 1994;20:314-8.

143. Bauchner H. Procedures, pain, and parents. Pediatrics 1991;87:563-5.

144. Margolius FR, Hudson KA, Michel Y. Beliefs and perceptions about children's pain: A survey. Pediatr Nurs 1995;21:111-5

145. Cassidy RC, Walco GA. Pediatric pain: Ethical issues and ethica management. Child Health Care 1996;25:253-64.
146. Salmon P, Manyande A. Good patients cope with their pain: Postoperative analgesia and nurses' perceptions of their patients' pain. Pain 1996;68:63-8.

147. McGrath PA. Development of the World Health Organization guidelines on cancer pain relief and palliative care in children. J Pain Symptom Manage 1996;12:87-92.

148. Ferrell BR. The impact of pain on quality of life. Nurs Clin North Am 1995;30:609-24

149. Nolan K. Ethical issues in pediatric pain management. In: Schechter NL, Berde CB, Yaster M, eds. Pain in Infants, Children and Adolescents. Baltimore: Williams \& Wilkins, 1993:123-31.

150. Ellis JA. Using pain scales to prevent undermedication. MCN Am J Matern Child Nurs 1988;13:180-2

151. Schechter NL, Sullivan CM. The ouchless place: No pain, children's gain. Pediatrics 1997;99:890-4.

152. Schechter NL, Zeltzer LK. Pediatric pain: new directions from a developmental perspective. J Dev Behav Pediatr 1999;20:209-10.

153. Kennedy RM, Luhmann JD. The "ouchless emergency department", Pediatr Clin North Am 1999;46:1215-46.

154. Cunliffe M. Guidelines in the management of pain in children. (Institutional pain protocol) Alder Hey Royal Liverpool Children's Hospital. Liverpool: NHS Trust, 1998.

155. Cunliffe M. Standards of care: Pain management. (Institutional Policy Statement) In: Pain and Symptom Management Manual. Memphis: St Jude's Children's Research Hospital, 2000:2.1.1-2.1.5.

156. Cunliffe M. Pediatric pain management policy. (Institutional Policy Statement). Iowa City: University of Iowa Hospital and Clinics, Dept of Nursing, Children and Women's Services, 1999.

157. Finley A, McGrath, P. Pediatric Pain: Science Helping Children, 1996. $<$ http://is.dal.ca/ pedpain/> (Version current at November 1, 2000)

158. Frandson JL. Pain resources on the Internet. In: McCaffery M, Pasero C, eds. Pain: Clinical Manual. St Louis: Mosby Inc, 1999:745-50.

159. O'Brien SW, Konsler GW. Alleviating children's postoperative pain. MCN Am J Matern Child Nurs 1988;13:183-6.

160. Preston Barnes L. Managing pain in children: Seek first to understand. MCN Am J Matern Child Nurs 1995;20:163.

161. Howell SL, Foster RL, Hester NO, Vojir CP, Miller KL. Evaluating a pediatric pain management research utilization program. Can J Nurs Res 1996;28:37-57.

162. Solomon R, Walco GA, Robinson MR. Pediatric pain management: program description and preliminary evaluation results of a professional course. J Dev Behav Pediatr 1998;19:193-5.

163. Kuttner LA. Child in Pain: How to Help, What to Do. Point Roberts: Hartley \& Marks, 1996.

164. Nethercott SG. The assessment and management of post-operative pain in children by registered sick children's nurses: An exploratory study. J Clin Nurs 1994;3:109-14.

165. Schechter NL. Common pain problems in the general pediatric setting. Pediatr Ann 1995;24:139,143-6.

166. Alexander M, Richtsmeier AJ, Broome ME, Barkin R. A multidisciplinary approach to pediatric pain: An empirical analysis. Child Health Care 1993;22:81-91.

167. Berde C, Cahill C. Multidisciplinary programs for pain management. In: Schechter NL, Berde CB, Yaster M, eds. Pain in Infants, Children and Adolescents. Baltimore: Williams \& Wilkins, 1993:349-53.

168. Wilson H. Painful facts. Nurs Times 1992;88:32-3 


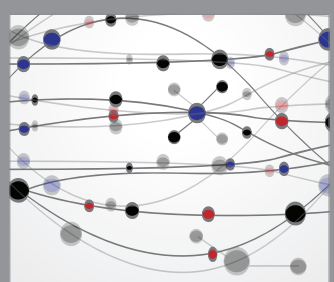

The Scientific World Journal
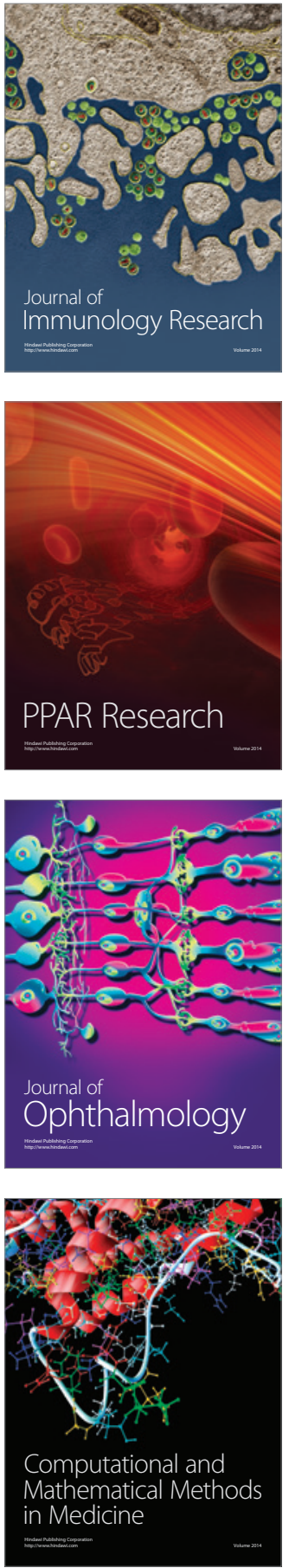

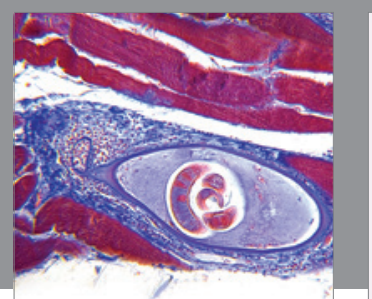

Gastroenterology Research and Practice

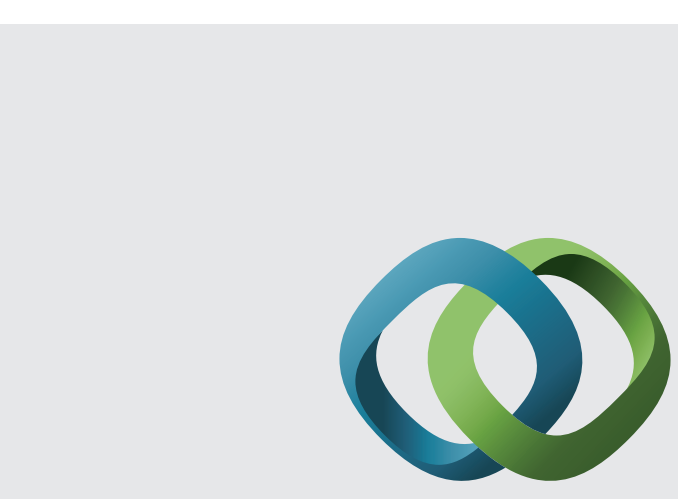

\section{Hindawi}

Submit your manuscripts at

http://www.hindawi.com
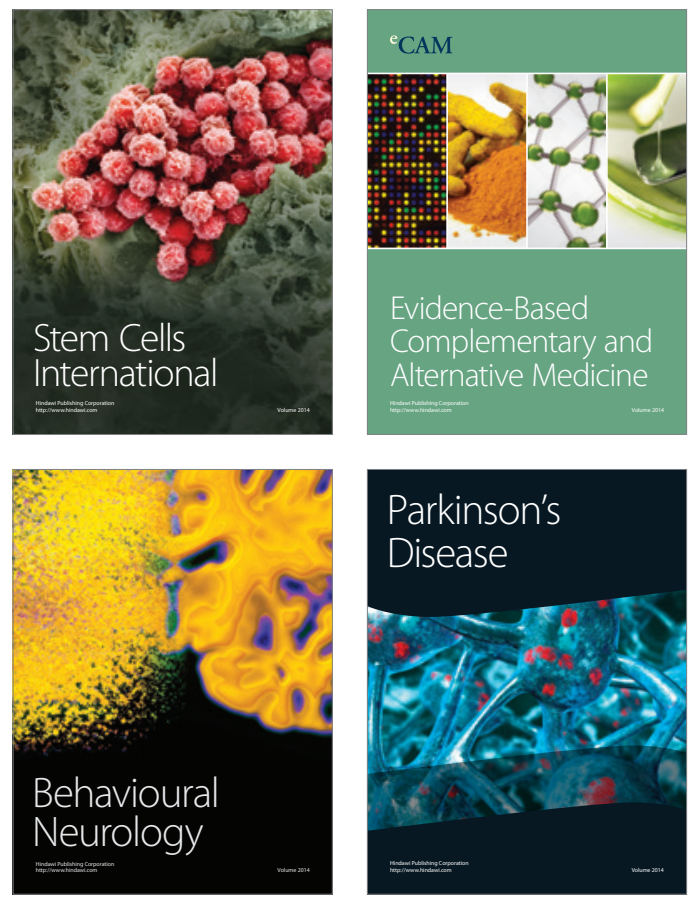
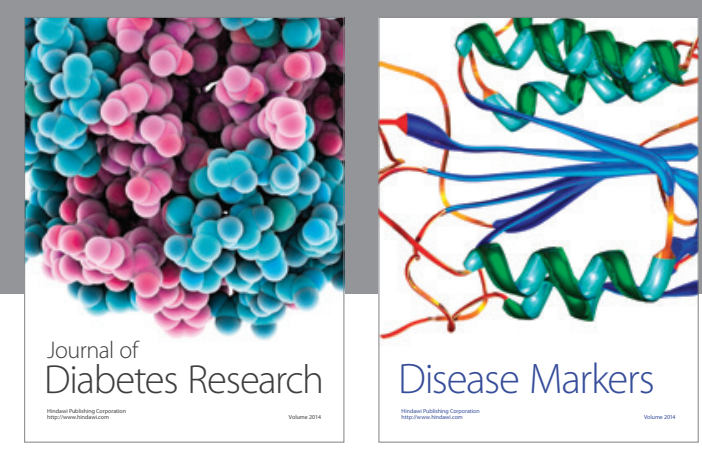

Disease Markers
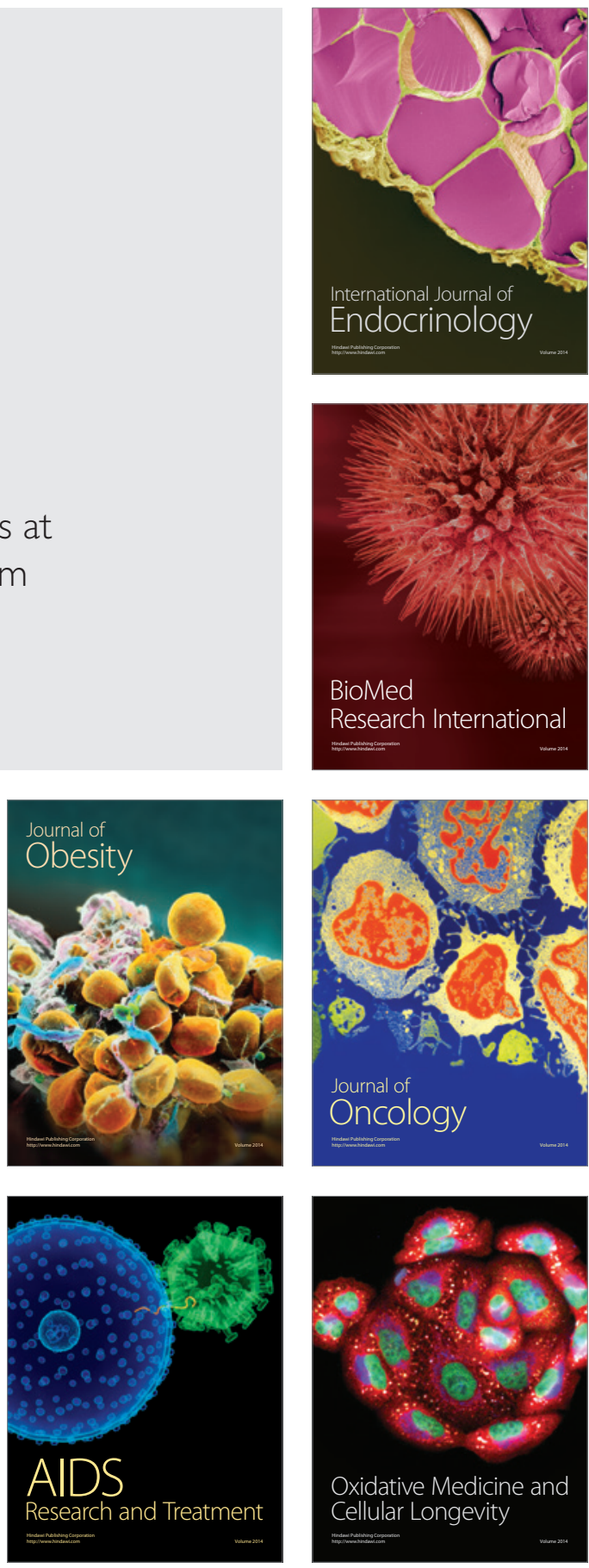